\title{
Characterization of concurrent Ku band tropospheric scintillation and rain attenuation in Malaysia
}

\author{
Ibtihal Fawzi Elshami ${ }^{1}$, Jafri Din², Lam Hong Yin ${ }^{3}$, Ali I Elgayar ${ }^{4}$ \\ ${ }^{1,4}$ College of Electrical and Electronics Technology-Benghazi, Libya \\ ${ }^{2}$ Wireless Communication Centre, Faculty of Electrical Engineering, Universiti Teknologi Malaysia, Malaysia \\ ${ }^{3}$ Department of Electrical Engineering Technology, Faculty of Engineering Technology, \\ Universiti Tun Hussein Onn Malaysia, Malaysia
}

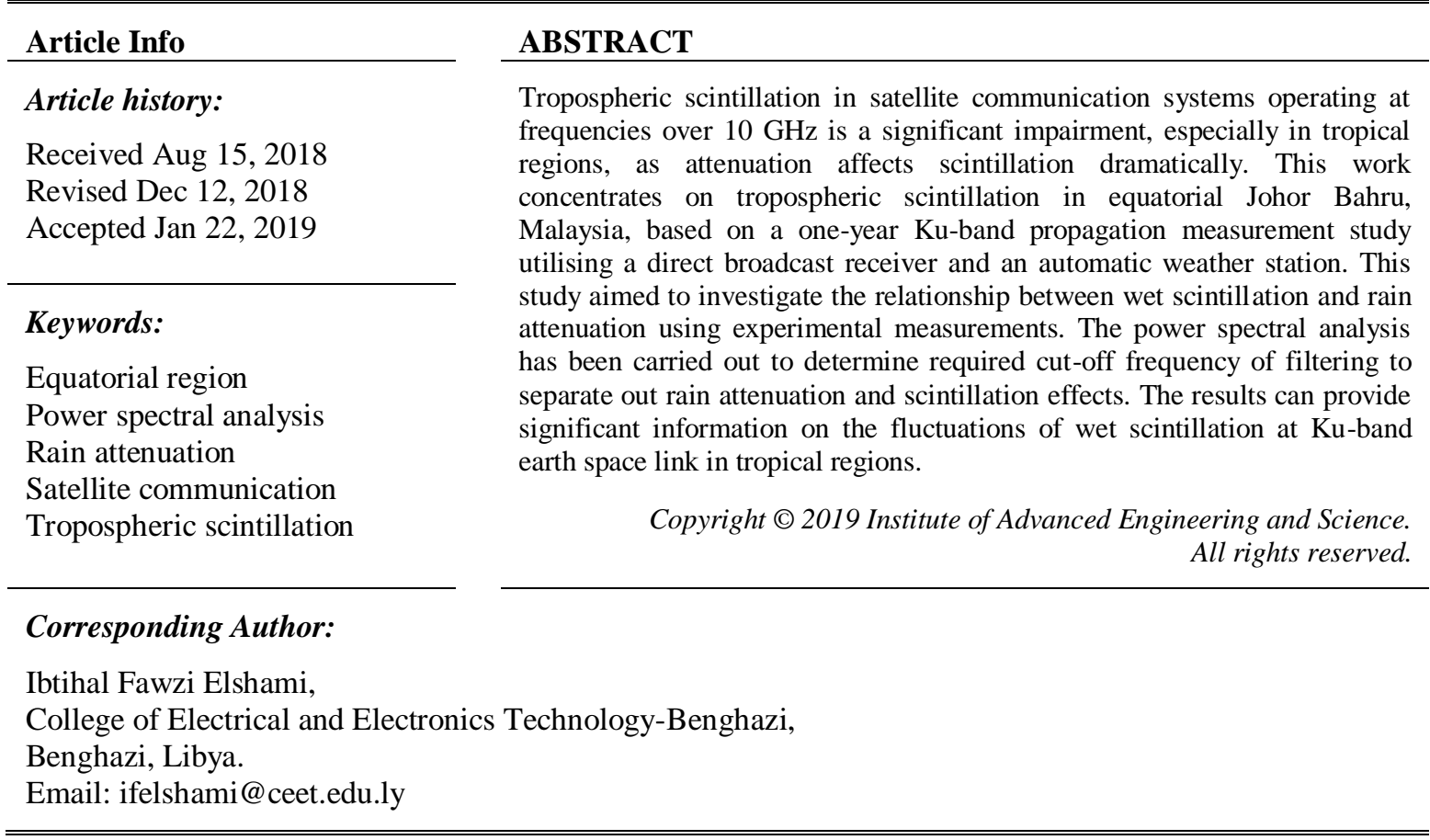

\section{INTRODUCTION}

Satellite communication systems operating at frequencies above $10 \mathrm{GHz}$ are heavily influenced by atmospheric effects, mainly rain attenuation. In order to efficiently use the channel capacity of a satellite, the amount of signal drop caused by the concurrent occurrence of wet scintillation and rain attenuation should be estimated. The rapid fluctuation of the received signal amplitude can range up to several decibels. The intensity of the fluctuations in the refractive index can produce significant impairments, as the margin of the communications systems decreases. This is common in places having frequencies above $10 \mathrm{GHz}$, particularly in tropical and equatorial regions, which has uniform temperature, high humidity and heavy rainfall $[1,2]$.

In order to efficiently using the channel capacity, the estimation of the amount of signal drop due to the concurrent occurrence of the rain attenuation and wet scintillations is significant [3]. This is prominent, especially in tropical and equatorial regions where convective rain is most frequent, although there have been some studies to understand and estimate the relationship between wet scintillation and rain attenuation in the temperate region [4-7]. However, there are only limited experimental results of wet scintillation in equatorial and tropical regions [8-12]. Therefore, it is worthwhile to further investigate and estimate the natural characteristics of wet scintillation and rain attenuation in tropical region.

Rain attenuation and scintillation are generally recognized by observing a change of spectrum slope in power spectral density of signal variation [4-6, 13, 14]. In general, the effect of rain attenuation only exists at a much lower frequency, while the scintillation tends to appear towards higher frequencies [15, 16].

According to several studies, a few types of filters were used to separate the scintillation and the attenuation effect. Initially, [15] it was suggested that, in order to filter out the scintillation effect, the 
2-minute moving average technique must be applied. Later, [17] it was reported that although the moving average was a remarkably good smoothing filter, it was an exceptionally bad low-pass filter especially in the action of a frequency domain. This is because the filter's roll-off was very slow and ripples existed at the stop band attenuation. Hence, the moving average filter was unable to separate one band of frequencies from another. Subsequently, the employment of the fifth-order Butterworth low-pass filter to eliminate the majority of the scintillation power [4-6]. It was reported that 0.025 of the cutoff frequency was used in lowpass filtering, in which the tropospheric scintillation appeared. In contrast, to remove the rain attenuation effect, a high pass filter with cutoff frequency $0.025 \mathrm{~Hz}[7,11]$ or Band-pass filter in the bandwidth $0.025-$ $0.5 \mathrm{~Hz}$ [4-6] was used.

Furthermore, this study has been a focus to separate wet scintillation and rain attenuation as much as possible, by filtering the time series of signal. Therefore, this study intends to explore those statistics in an equatorial site by exploiting the propagation measurements carried out in tropical region. This work will be a helping hand in providing knowledge for characterizing wet scintillation and rain attenuation.

A description of the measurement setup is given in Section 2. Data analysis procedures and discussions about wet scintillation and rain attenuation are presented in Section 3 and Section 4. Conclusions are given in Section 5 .

\section{EXPERIMENTAL SETUP}

The experimental station installed in the premises of tropical region [18-19]. The experimental setup was collected for one year, situated at $103.64^{\circ} \mathrm{E}$ and $1.55^{\circ} \mathrm{N}$ consist of one direct broadcast receiving antenna with a diameter of $90 \mathrm{~cm}$, pointed toward MEASAT-3, broadcasting satellite at the elevation angle of $75.61^{\circ}$. The signal of the satellite would reach the parabolic antenna, and then directed into the Low Noise Block (LNB), or simply known as the Radio Frequency (RF) box. The Ku-band signal would be amplified and down-converted into $1 \mathrm{GHz}$ Intermediate Frequency (IF) signal. The broadcasting signal at $12.2 \mathrm{GHz}$ is monitored and recorded through spectrum analyzer and data logger as depicted in Figure 1. Automatic Weather Station (AWS) is also located A meteorological station, equipped with various sensors to provided several surface parameters such as temperature, humidity, and wind speed and direction and a tipping bucket rain gauge, is also located near the receiver antenna.

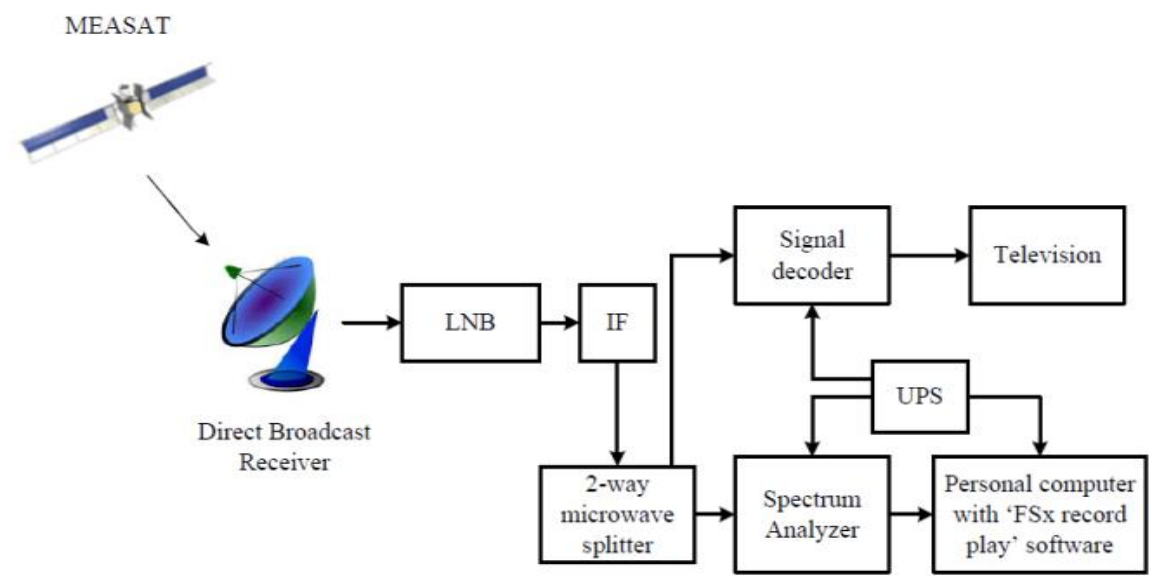

Figure 1. Block diagram of MEASAT satellite receiving system

\section{RAIN ATTENUATION AND WET SCINTILLATION DATA ANALYSIS}

In order to recognize between the rain attenuation (signal fluctuations due to scattering and absorption of hydrometeors) and scintillation (signal fluctuations due to air turbulence), the two effects must be separated as much as possible, by filtering the time series of signal [15].

The experimental data set was divided into rain periods and clear sky periods. The start and end of a rain event were manually identified from the observation of the rain rate time series, concurrently collected from the rain gauge [7]. A quality inspection was performed on all data to achieve to detect any false and invalid data behaviour of the received signal. In spite of the fact that this phenomenon is not always true for all rain events, sometimes the signal level may be affected by the presence of the rain along a slant propagation path while the rain intensity is measured only based on onsite reception signal. 
The time series of the received signal would need to be low-pass filtered to remove rapid fluctuation, and high-pass filtered to take off rain attenuation. In this work, the separation of scintillation effects and rain attenuation was achieved by using a fifth-order Butterworth filter. Butterworth filter is considered as a very popular filter because of its best approximation to the ideal filter in the sense of maximal flatness in the filter passband. Also, the fifth order of the filter is used as the magnitude characteristics approach to the ideal filter [20]. The cut-off frequency used in this study was $0.02 \mathrm{~Hz}$ as shown in Figure 2(a) for convective rain event from MEASAT-3. Such cutoff frequency, determined from the power spectrum of signal variations as the power spectra of rain attenuation and scintillation, had different log-slopes [5]. For instance, rain attenuation had a slope of $-20 \mathrm{~dB} / \mathrm{decade}$, whereas scintillation had a slope of $-80 / 3 \mathrm{~dB} / \mathrm{decade}$. This is clearly evidenced in Figure 2(a), when the two decades on the Y-axis are equivalent to $-20 \mathrm{~dB} / \mathrm{decade}$ slope up to $0.02 \mathrm{~Hz}$, followed by a typical tropospheric scintillation power spectrum with $-80 / 3 \mathrm{~dB} / \mathrm{decade}$ slope, extended up to Nyquist frequency at $0.5 \mathrm{~Hz}$ for MEASAT-3 [4].

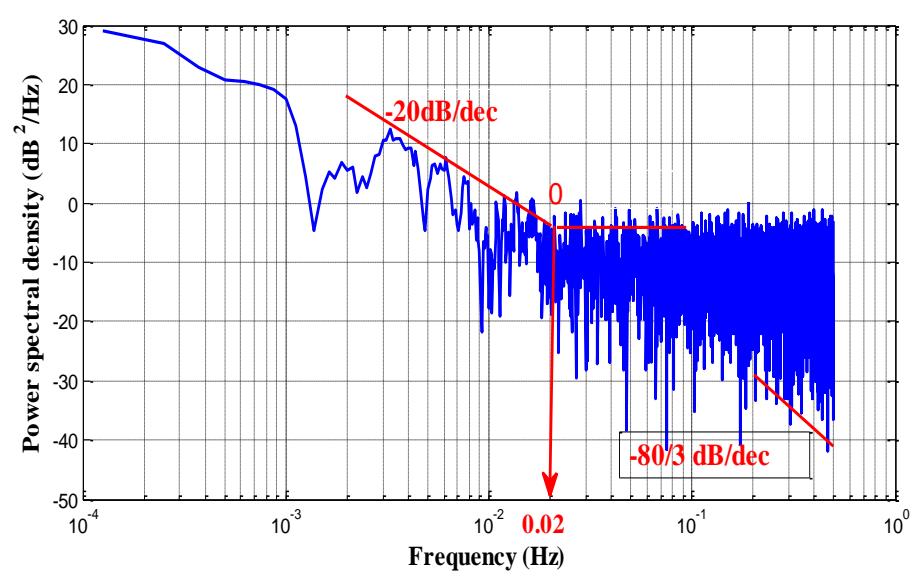

(a)

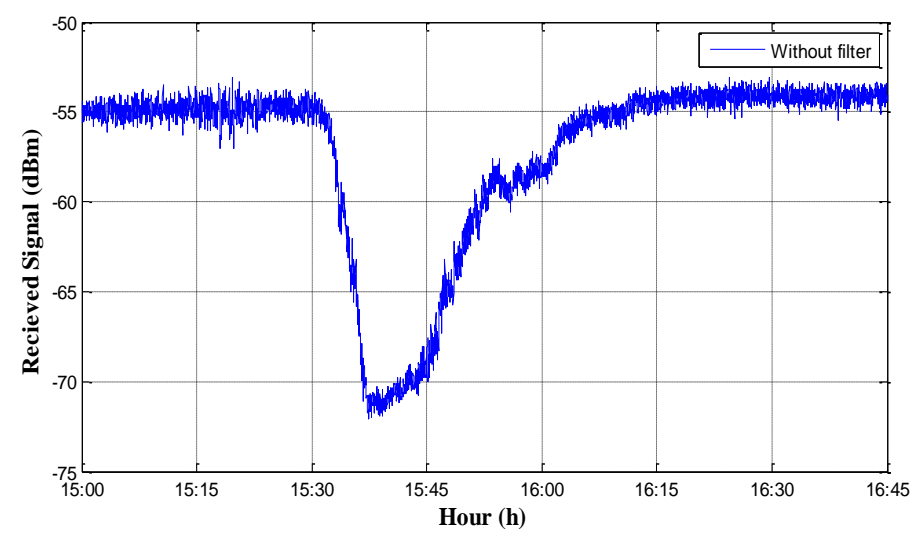

(b)

Figure 2. (a) Power spectral density, (b) corresponding time series of received signal on 31st December 2013 for MEASAT-3

\section{RESULTS AND DISCUSSION}

The impact of the two phenomena can be assessed from the power spectra of the high- and low-pass filtered signal level data having different slopes. The received signal was filtered using low pass filter with $\mathrm{f}_{\mathrm{c}}=0.2$, to obtain rain attenuation. Meanwhile, High- pass filtered scintillations with $\mathrm{f}_{\mathrm{c}}=0.2$ for MEASAT3 satellite. Figure 3(a) and (b) show low-pass filtered rain attenuation and high-pass filtered scintillations, respectively for the rain event, as illustrated in Figure 2(b). 


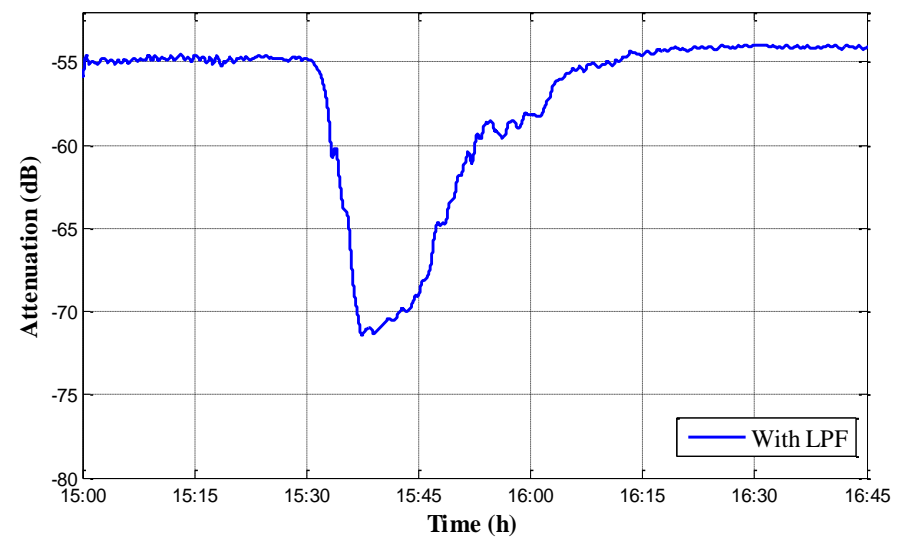

(a)

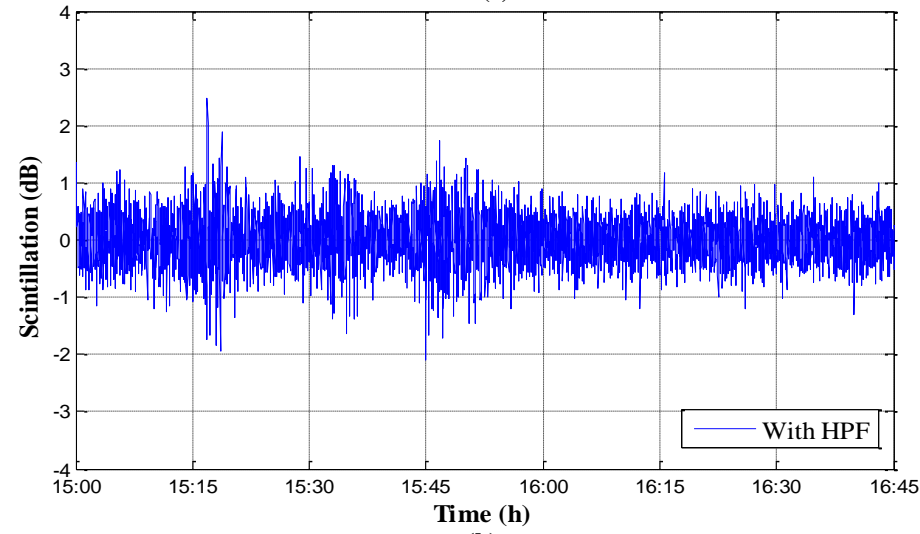

(b)

Figure 3. MEASAT-3 received signal level (a) With LPF, (b) With HPF

The complementary cumulative distribution functions (CCDFs) of wet scintillation amplitude statistic from the measurements at Johor Bahru relative to the one-year period. Figure 4 shows that fade scintillation is higher than enhancement scintillation. The figure also shows the CCDF of scintillation fades at $0.01 \%$ of the time was $0.96 \mathrm{~dB}$, and approximately $0.95 \mathrm{~dB}$ of scintillation enhancements. Furthermore, there was about $1.45 \mathrm{~dB}$ scintillation fades at $0.001 \%$ of the time, and approximately $1.4 \mathrm{~dB}$ scintillation enhancements.

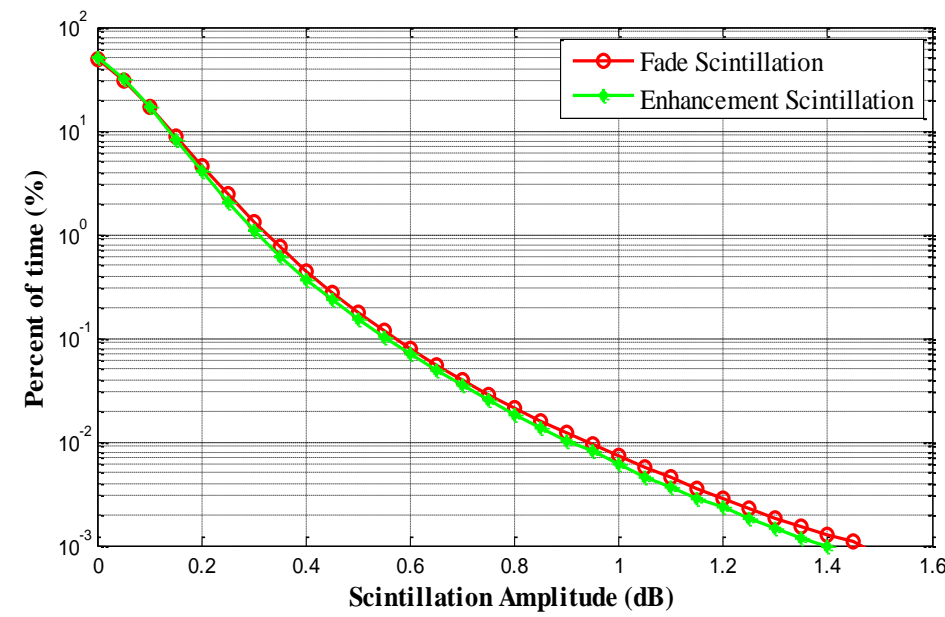

Figure 4. Complementary cumulative distribution function (CCDF) of the measured scintillation fade and enhancement in equatorial Johor Bahru 


\section{CONCLUSION}

Wet scintillation characteristics in tropical and equatorial regions were intensively investigated. The raw data collected from a measurement campaign carried out in tropical region needed to be processed carefully before any analysis was performed. Besides, the collected signal was processed and separated into clear-sky and rainy events based on rain rate data from a rain gauge located near the receiving antenna. Similarly, for rainy events, a signal quality assessment to eliminate anomalous signals was necessary. The results showed that the fifth-order Butterworth low pass filter with 0.02 cutoff frequency was eliminate the majority of the scintillation power. In contrast, the fifth-order Butterworth high pass filter with 0.02 cutoff frequency was used to remove the rain attenuation effect. Furthermore, the results clearly pointed out that CCDF of wet scintillation amplitude of one year measurement data shows a higher scintillation fade compared with scintillation enhancement. Such findings provide information is of great interest for the system designers to appropriately design fade margin.

\section{ACKNOWLEDGEMENTS}

This work has been funded by Ministry of Education Malaysia and UTM under "FRGS" Vot. No. R.J.130000.7823.4F958, and UTHM Tier 1 Grant Vot. No. H160.

\section{REFERENCES}

[1] M. M. Yunus, et al., "Interfade Duration Statistics at Ku-band for Satellite Earth Links System in Equatorial Malaysia: Modeling Distribution," TELKOMNIKA (Telecommunication Computing Electronics and Control), vol. 15, pp. 964-970, 2017.

[2] M. M. Nia, et al., "Stochastic Approach to a Rain Attenuation Time Series Synthesizer for Heavy Rain Regions," International Journal of Electrical and Computer Engineering (IJECE), vol. 6, pp. 2379-2386, 2016.

[3] M. Filip and E. Vilar, "Optimum utilization of the channel capacity of a satellite link in the presence of amplitude scintillations and rain attenuation," Communications, IEEE Transactions on, vol. 38, pp. 1958-1965, 1990.

[4] E. Matricciani, et al., "Relationship between scintillation and rain attenuation at $19.77 \mathrm{GHz}$," Radio Science, vol. 31, pp. 273-279, 1996.

[5] E. Matricciani, et al., "Scintillation and simultaneous rain attenuation at $12.5 \mathrm{GHz}$ to satellite Olympus," Radio Science, vol. 32, pp. 1861-1866, 1997.

[6] E. Matricciani and C. Riva, "18.7 GHz tropospheric scintillation and simultaneous rain attenuation measured at Spino d'Adda and Darmstadt with Italsat," Radio Science, vol. 43, 2008.

[7] P. Garcia-del-Pino, et al., "Tropospheric scintillation with concurrent rain attenuation at $50 \mathrm{GHz}$ in Madrid," Antennas and Propagation, IEEE Transactions on, vol. 60, pp. 1578-1583, 2012.

[8] A. Maitra and A. Adhikari, "Scintillations of Ku Band Satellite Signal Related to Rain Attenuation at a Tropical Location," presented at the National Workshop on Atmospheric and Space Sciences, 2010.

[9] J. Suryana, et al., "Two years characterization of concurrent Ku-band rain attenuation and tropospheric scintillation in Bandung, Indonesia using JCSAT3," in Information, Communications and Signal Processing, 2005 Fifth International Conference on, 2005, pp. 1585-1589.

[10] T. Marsault, et al., "EHF propagation experiment with SYRACUSE 3 satellite: First results," in Antennas and Propagation, 2007. EuCAP 2007. The Second European Conference on, 2007, pp. 1-6.

[11] A. Adhikari and A. Maitra, "Studies on the inter-relation of Ku-band scintillations and rain attenuation over an Earth-space path on the basis of their static and dynamic spectral analysis," Journal of atmospheric and solarterrestrial physics, vol. 73, pp. 516-527, 2011.

[12] H. Dao, et al., "Effect of rain induced scintillation on Ku-band satellite link in tropical region," in Engineering Technology and Technopreneuship (ICE2T), 2014 4th International Conference on, 2014, pp. 222-225.

[13] E. Matricciani, "Physical-mathematical model of dynamics of rain attenuation with application to power spectrum," Electronics Letters, vol. 30, pp. 522-524, 1994.

[14] E. Matricciani, et al., "Scintillation and simultaneous rain attenuation at $49.5 \mathrm{GHz}$," in Antennas and Propagation, 1995., Ninth International Conference on (Conf. Publ. No. 407), 1995, pp. 165-168.

[15] Y. Karasawa and T. Matsudo, "Characteristics of fading on low-elevation angle earth-space paths with concurrent rain attenuation and scintillation," Antennas and Propagation, IEEE Transactions on, vol. 39, pp. 657-661, 1991.

[16] I. F. El-Shami, et al., "Tropospheric Scintillation with Rain Attenuation of Ku Band at Tropical Region," TELKOMNIKA Telecommunication Computing Electronics and Control, vol. 16, pp. 1982-1987, 2018.

[17] S. W. Smith, "The scientist and engineer's guide to digital signal processing," 1997.

[18] I. F. El-Shami, et al., "Clear Sky Diurnal Behavior of Tropospheric Scintillation at Ku-Band Satellite Communication In Equatorial Malaysia,” Jurnal Teknologi, vol. 77, 2015.

[19] I. F. Elshami and J. Din, "Seasonal and Diurnal Variation on Tropospheric Scintillation at Ku-Band in Tropical Climate," International Journal of Electrical and Computer Engineering, vol. 6, pp. 1710, 2016.

[20] S. Bernard, "Digital communications fundamentals and applications," Prentice Hall, USA, 2001. 


\section{BIOGRAPHIES OF AUTHORS}
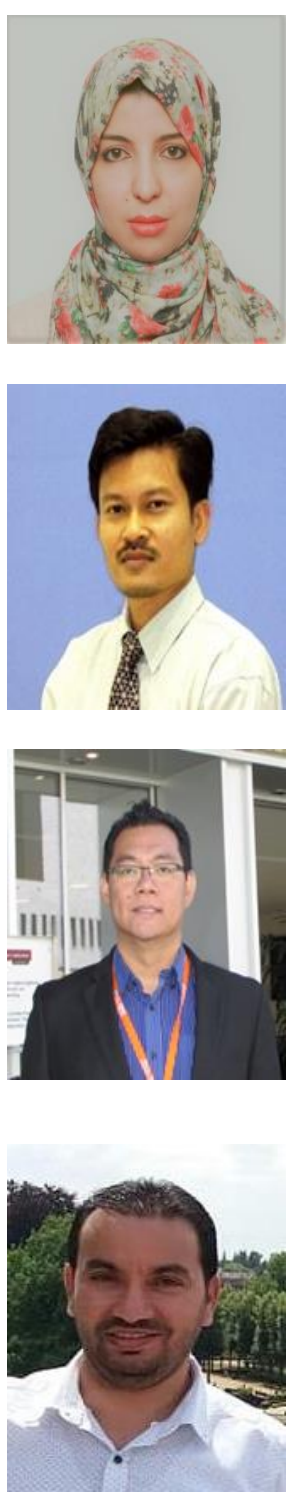

Ibtihal Fawzi Elshami is a senior lecturer and the director of the International Corporation Office (ICO) at the College of Electrical and Electronics Technology-Benghazi in Benghazi-Libya. She obtained her Ph.D in electrical engineering from University Technology Malaysia (UTM) in this 2016. She joined UTHM university as master student and obtained her M.Sc. degree in electrical engineering in 2011. She received her bachelor's degree of electrical engineering from Benghazi University at Libya in 2006. Her research interests are in the field of radiowave propagation with respect to satellite communication and terrestrial telecommunication link.

Prof. Dr. Jafri Bin Din received his BSEE in Electrical Engineering from Tri-State University, Indiana USA in 1988 and his Ph.D from Universiti Teknologi Malaysia, Johor, Malaysia in 1997. He has been Head of Departments, Undergraduate Academic Manager Deputy Dean (Development) in Faculty of Electrical Engineering (FKE) UTM from 2008 till 2013. He is currently the Deputy Director of Wireless Communication Center (WCC) UTM. His research activities have been correlated to the field of radio wave propagation, satellite propagation and communications, High Altitude platform stations (HAPS), Satellite TV broadcasting, Weather Radar and sound technique for fisheries Industry.

Hong Yin Lam received the M. Eng. and the Ph.D. degrees in electrical engineering and telecommunication from the Universiti Teknologi Malaysia (UTM), Johor, Malaysia, in 2009 and 2013, respectively. He then served as a postdoctoral fellow in the Department of Communication Engineering (UTM), Johor, Malaysia. He is currently a lecturer at Faculty of Engineering Technology, Universiti Tun Hussein Onn, Malaysia, since 2007. His research activities have been relative to the field of radio wave propagation through the atmosphere, with specific focus on rain (rain drop size distribution and structures characterization) for propagation applications. Lam is a recipient of the Young Scientist Awards at the International Symposium on Antennas and Propagation (ISAP), Japan, in 2012, and Asia Pacific Radio Science Conference, Taiwan, in 2013.

Ali I Elgayar is the director of research center at the College of Electrical and Electronics Technology-Benghazi in Benghazi, Libya. He obtained his Ph.D. from UTM university. He received his Bachelor's degree of electrical engineering from Benghazi University, Libya in 2005. He was work as field engineer at Schlumberger company from 2005 to 2006, and then he moved to Halliburton oil company to work as logging engineer from 2006 to 2009. He joined UTHM university as master student and obtained his M.Sc. degree in electrical engineering in 2011, His research interests are high voltage, transmission line, gas and oil pipeline, induced voltages and lightning. 